\title{
Time profile of nimotuzumab for enhancing radiosensitivity of the Eca109 cell line
}

\author{
JIANCHENG LI*, LINGHUA WANG ${ }^{*}$, ZIDAN QIU and YING SU \\ Department of Radiation Oncology, Fujian Provincial Tumor Hospital, \\ Provincial Clinical College of Fujian Medical University, Fuzhou, Fujian 350014, P.R. China
}

Received February 16, 2017; Accepted August 16, 2018

DOI: $10.3892 / \mathrm{ol} .2019 .9897$

\begin{abstract}
The aim of the present study was to investigate the ability of Nimotuzumab to increase radiosensitivity at different delivery times in the mixed cancer cell line Eca109, to determine the optimal delivery time. Cultured Eca109 cells were classified into five groups: Control with no treatment (O group); irradiation without Nimotuzumab treatment (R group); treatment with Nimotuzumab $24 \mathrm{~h}$ prior to or after irradiation (24NR or 24RN group, respectively); and Nimotuzumab combined with irradiation simultaneously (NR group). Following cells reaching the logarithmic-growth phase, cell survival after exposure to Nimotuzumab was evaluated using an MTT assay; thereafter, the $50 \%$ inhibitory concentration $\left(\mathrm{IC}_{50}\right)$ of the cell line was calculated. Cell-survival curves were generated using a colony-forming assay. Flow cytometry analysis was used to detect apoptosis rates and cell-cycle distribution. The expression level of epidermal growth factor receptor was measured in Eca109 cells with western blotting. Growth inhibition was only observed $72 \mathrm{~h}$ after exposure to Nimotuzumab. The $\mathrm{IC}_{50}$ was $768 \mu \mathrm{g} / \mathrm{ml}$. At a dose of $0.2 \mathrm{IC}_{50}$ or $0.3 \mathrm{IC}_{50}$, the sensitization enhancement ratio of radiosensitivity was highest in the 24NR group. Nimotuzumab enhanced radiation-induced apoptosis in Eca109 cells, with the optimal delivery time at $24 \mathrm{~h}$ prior to irradiation $(\mathrm{P}=0.035)$. The concentration of Nimotuzumab administered was directly proportional to the increase in radiosensitivity of the cells.
\end{abstract}

\section{Introduction}

In China, esophageal cancer (EC) is ranked sixth and second for the number of reported cases and mortality, respectively (1).

Correspondence to: Dr Jiancheng Li, Department of Radiation Oncology, Fujian Provincial Tumor Hospital, Provincial Clinical College of Fujian Medical University, 420 Fuma Road, Fuzhou, Fujian 350014, P.R. China

E-mail: cnjianchengli@126.com

*Contributed equally

Key words: nimotuzumab, esophageal squamous cancer cell line, radiosensitivity delivery time
Additionally, the most common pathological type of EC is esophageal squamous cell carcinoma (ESCC) (2). Of patients with EC, $\sim 70 \%$ are diagnosed with advanced and inoperable EC (3). Furthermore, even following treatment with chemotherapy and definitive or neoadjuvant chemoradiotherapy, the outcome remains poor, with a 5-year overall survival rate of $<15 \%$ (4). It is therefore important to identify and develop novel therapies and treatments for EC.

Recent research has focused on the role of the epidermal growth factor receptor (EGFR) signaling pathways in the progression of EC $(5,6)$. EGFR is a prototypic cell-surface receptor that belongs to the ErbB/HER oncogene family (7). Additionally, EGFR overexpression or mutations have been reported to serve an important role in tumorigenesis in various EC types (8), and also participate in the development of resistance to chemotherapy and radiation $(9,10)$. It has been demonstrated that EGFR inhibitors alone may be used to treat a number of tumor types, such treatments cause fewer side effects compared with traditional chemotherapy $(11,12)$, and notably improve the local control rate when combined with radiotherapy $(13,14)$.

EGFR inhibitors, including small-molecule EGFR tyrosine kinase inhibitors (TKIs) and monoclonal antibodies, are utilized for clinical treatment of EC. TKIs, including gefitinib and erlotinib, repress EGFR phosphorylation and inhibit downstream signals of EGFR (15). Monoclonal antibodies, including cetuximab and nimotuzumab, have the ability to bind to the extracellular domain of EGFR to prevent EGFR receptor dimerization and the activation of its intracellular tyrosine kinase (16). These drugs have been demonstrated to have a notable radiosensitizing effect and are frequently administered in combination with radiotherapy, whether during a short time period or simultaneously (17). However, the optimal delivery time for EGFR inhibitors has not been determined and administration of these inhibitors at the wrong time may reduce the effects of combined therapy (18). In the present study, the aim was to determine the optimal time for administration of nimotuzumab to enhance its radiosensitizing effect in EC.

\section{Materials and methods}

Cell culture. Human Eca109 cells were obtained from the Shanghai Institute of Biochemistry and Cell Biology (Shanghai, China) and maintained at the Fujian Provincial Key 
Laboratory of Translational Cancer Medicine (Fuzhou, China). Cells were cultured in RPMI-1640 containing 10\% fetal calf serum (Gibco; Thermo Fisher Scientific, Inc., Waltham, MA, USA), $100 \mathrm{U} / \mathrm{ml}$ penicillin and $100 \mu \mathrm{g} / \mathrm{ml}$ streptomycin at $37^{\circ} \mathrm{C}$ in a humidified air-incubator with an atmosphere containing $5 \% \mathrm{CO}_{2}$. Notably, the Eca109 cell line has been reported to be contaminated with cervical carcinoma HeLa cells, as reported by Ye et al (19).

Small interfering RNAs (siRNAs). siRNAs were transfected into cells using Lipofectamine ${ }^{\circledR} 2000$ (Invitrogen; Thermo Fisher Scientific, Inc.), according to the manufacturer's instructions. Briefly, cells were seeded in a 6-well plate at a density of $5 \times 10^{4}$ cells/well $24 \mathrm{~h}$ prior to transfection. siRNA complexes were added to cells when cultures reached $50 \%$ confluence at a final concentration of $50 \mathrm{nM}$ in the absence of serum. Following incubation at $37^{\circ} \mathrm{C}$ for $4 \mathrm{~h}$, the culture medium (Opti-MEMI low serum medium; cat. no. 31985-062) was replaced with $2 \mathrm{ml}$ fresh Opti-MEMI medium supplemented with $10 \%$ fetal bovine serum (both Thermo Fisher Scientific, Inc.). Cells were cultured under standard conditions $\left(37^{\circ} \mathrm{C}\right)$ for a further $72 \mathrm{~h}$ before being examined by western blot analysis.

A total of three different sequences of siRNA used in the experiment, including EGFR siRNA , EGFR siRNA $_{2}$ and EGFR siRNA ${ }_{3}$, which were designed by Invitrogen; Thermo Fisher Scientific, Inc., to determine the most effective RNA interference sequence. For the negative control (NC) a random sequence siRNA(-) was used. NC siRNA(-) forward, 5'-CGU GAUUGCGAGACUCUGAdTdT-3' and reverse, 3'-dTdTGC ACUAACGCUCUGAGACU-5', which were also obtained from Thermo Fisher Scientific, Inc. (Invitrogen; Thermo Fisher Sientific, Inc.). The siRNAs used were as follows: EGFR siRNA ${ }_{1}$ forward, 5'-UGAUCUGUCACCACAUAAUUACGG G-3' and reverse, 3'-CCCGUAAUUAUGUGGUGACAGAUC A-5'; EGFR siRNA 2 forward, 5'-UUAGAUAAGACUGCU AAGGCAUAGG-3' and reverse, 3'-CCUAUGCCUUAGCAG UCUUAUCUAA-5'; and EGFR siRNA ${ }_{3}$ forward, 5'-UUUAA AUUCACCAAUACCUAUUCCG-3' and reverse, 3'-CGGAA UAGGUAUUGGUGAAUUUAAA-5'.

Western blot analysis. Cells were seeded at a density of $1 \times 10^{3}$ cells/well in 3-well plates for $48 \mathrm{~h}$ and washed for 5 min three times in ice-cold PBS. Protein was extracted using radioimmunoprecipitation assay lysis buffer (Wuhan Boster Biological Technology Co., Ltd., Wuhan, China). Total protein $(20 \mu \mathrm{g} / \mathrm{lane})$ was separated by $10 \%$ SDS-PAGE and transferred to a polyvinylidene fluoride membrane (EMD Millipore, Billerica, MA, USA), followed by incubation with $10 \mathrm{ml} 5 \%$ skim milk at room temperature for $1 \mathrm{~h}$. A primary antibody against EGFR (cat. no. ab40815; 1:500; Abcam, Cambridge, UK) and $\beta$-tubulin (cat. no. 2128; Cell Signaling Technology Inc., Danvers, MA, USA) was used as the loading control at $4^{\circ} \mathrm{C}$ overnight. A horseradish peroxidase-conjugated goat anti-rabbit IgG (cat. no. A0277; 1:2,500; Beyotime Institute of Biotechnology, Shanghai, China) was used as the secondary antibody at room temperature for $2 \mathrm{~h}$. Subsequently, the coloration was completed by DAB (Sigma-Aldrich; Merck KGaA, Darmstadt, Germany). Images were captured with a Bio-Rad Gel Doc XR and Quantity One v4.6.8 (Bio-Rad Laboratories, Inc., Hercules, CA, USA).
A
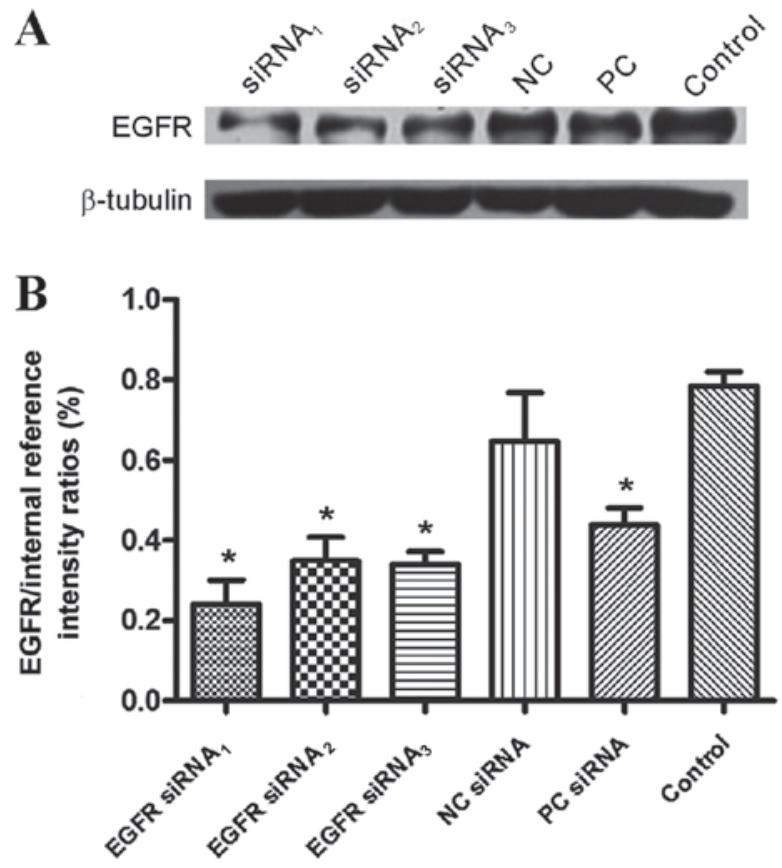

Figure 1. Local expression of EGFR protein determined by western blotting in the Eca109 cell line. (A) Western blot bands. (B) Intensity ratio of target and internal reference bands. A total of 3 different sequences of siRNA (EGFR siRNA ${ }_{1}$, EGFR siRNA End EGFR siRNA $_{3}$ ) were used to determine the most effective RNA interference sequence. " $\mathrm{P}<0.05$, compared with group O; siRNA, small interfering RNA; NC, negative control siRNA(-); $\mathrm{PC}$, positive control siRNA(+); EGFR, epidermal growth factor receptor.

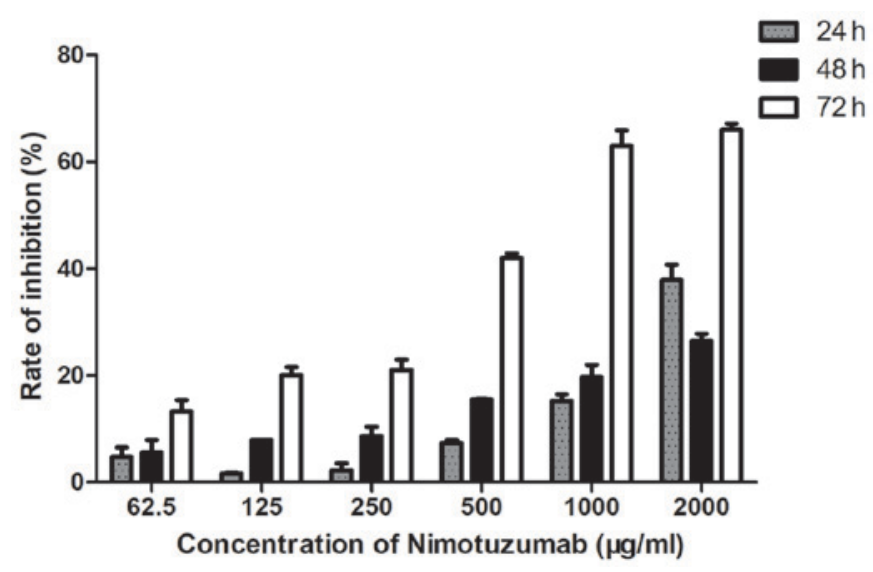

Figure 2. Inhibition effects of nimotuzumab at different concentrations and administered for 24,48 or $72 \mathrm{~h}$ in the Eca109 cell line.

MTT assay. Cells in the logarithmic-growth phase were cultured in 96 -well plates at a density of $1 \times 10^{5}$ cells/well in triplicate. Following incubation for $24 \mathrm{~h}$, nimotuzumab (Trinity Biotech Plc, Beijing, China) was added at concentrations of $2,000,1,000,500,250,125$ or $62.5 \mu \mathrm{g} / \mathrm{ml}$. MTT (50 $\mu \mathrm{l}$; Amresco, LLC, Solon, OH, USA) was added following incubation at $37^{\circ} \mathrm{C}$ for 24,48 or $72 \mathrm{~h}$, followed by the addition of $150 \mu$ l dimethyl sulfoxide (Sigma-Aldrich; Merck KGaA) into each well. A microplate reader was used to determine the absorbance of the formed product at $570 \mathrm{~nm}$ [optical density $\left.(\mathrm{OD})_{570}\right]$. Cell viability (\%) was calculated as follows: $\left(\mathrm{OD}_{\text {sample }}-\mathrm{OD}_{\text {blank }}\right) /\left(\mathrm{OD}_{\text {control }}-\mathrm{OD}_{\text {blank }}\right) \times 100$. The $\mathrm{IC}_{50}$ was also calculated. 
Table I. Radiation biology parameters of Eca109 cells fitted using a multi-target model.

\begin{tabular}{llcccc}
\hline Drug doses, $\mu \mathrm{g} / \mathrm{ml}$ & Group & D0 & Dq & NR & SER \\
\hline \multirow{3}{*}{150} & $\mathrm{R}$ & 1.65 & 3.75 & 2.27 & - \\
& $24 \mathrm{NR}$ & 1.52 & 6.64 & 4.36 & 1.09 \\
& $\mathrm{NR}$ & 1.66 & 2.93 & 1.76 & 0.99 \\
200 & $24 \mathrm{RN}$ & 1.88 & 2.22 & 1.18 & 0.88 \\
& 24NR & 1.35 & 3.24 & 2.39 & 1.22 \\
& NR & 1.58 & 2.88 & 1.81 & 1.04 \\
& 24RN & 1.68 & 3.36 & 2.0 & 0.98 \\
\hline
\end{tabular}

$\mathrm{R}$, irradiation without nimotuzumab treatment; 24NR, treatment with nimotuzumab $24 \mathrm{~h}$ prior to irradiation; $24 \mathrm{RN}$, treatment with nimotuzumab $24 \mathrm{~h}$ after irradiation; NR, nimotuzumab combined with irradiation simultaneously; SER, sensitization enhancement ratio; D0, mean lethal dose; Dq, quasi-threshold dose.

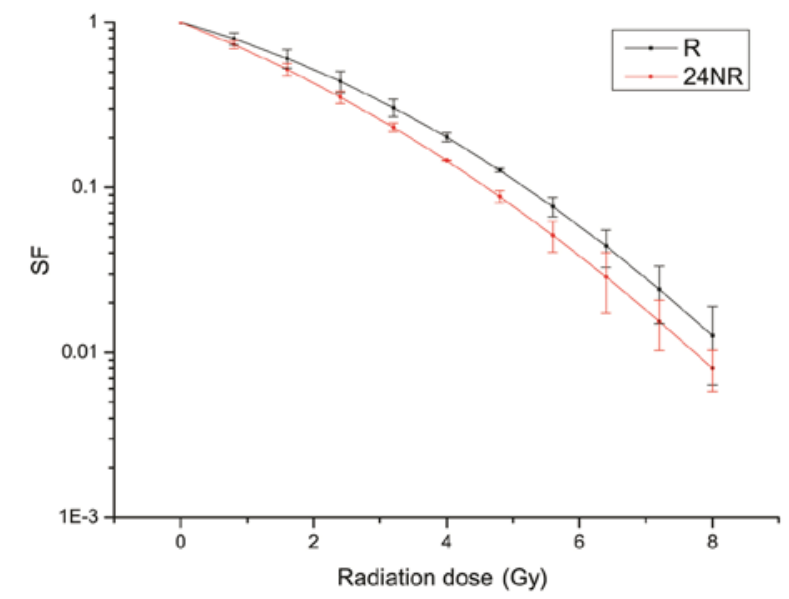

Figure 3. Survival curve of nimotuzumab administration in the $24 \mathrm{NR}$ and $\mathrm{R}$ groups. SF, surviving fraction; $\mathrm{R}$, irradiation without nimotuzumab treatment; $24 \mathrm{NR}$, treatment with nimotuzumab $24 \mathrm{~h}$ prior to irradiation.

Radiation and colony formation assay. Cells were seeded at a density of $6 \times 10^{5}$ cells/well in 3 -well plates with a 60-mm diameter. Cultured cells were divided into five groups: Control without any treatment (O group); irradiation without nimotuzumab treatment ( $\mathrm{R}$ group); treatment with nimotuzumab $24 \mathrm{~h}$ prior to irradiation (24NR group); nimotuzumab $24 \mathrm{~h}$ after irradiation (24RN group); and nimotuzumab administered with irradiation simultaneously (NR group) Nimotuzumab was administered at different doses, including 2,000, 1,000, 500, 250, 125 and $62.5 \mu \mathrm{g} / \mathrm{ml}$. Cells were irradiated using a Synergy linear accelerator (Siemens AG, Munich, Germany) at $6 \mathrm{MV}$ exposure with a source-skin distance of $100 \mathrm{~cm}$ at a rate of $3 \mathrm{~Gy} / \mathrm{min}$ and a field of $20 \times 20 \mathrm{~cm}$. Cells were irradiated with doses of $0,1,2,4,6$ or $8 \mathrm{~Gy}$, with three complex holes for each dose. Following irradiation, cells were cultured at $37^{\circ} \mathrm{C}$ for 14 days. The number of colonies with $>50$ cells was recorded by eye. The plating efficiency (\%) was determined as follows: (Number of clones/inoculated cells) x100. The surviving fraction (SF; \%) was determined as follows:
(Colony formation rate of irradiated cells/colony formation rate of control cells) x100. Origin 7.5 software (OriginLab, Northampton, MA, USA) was used to calculate the mean lethal dose (D0), quasi-threshold dose (Dq), SF and sensitization enhancement ratio (SER). The SER of different groups were analyzed at a dosage of $0.2 \mathrm{IC}_{50}$ and $0.3 \mathrm{IC}_{50}$.

Apoptosis and cell cycle distribution analysis. Trypsin-digested $\left(37^{\circ} \mathrm{C}\right.$ for $3 \mathrm{~min}$ ) Eca109 cells were filtered to prepare a cell suspension. Annexin-V-fluorescein isothiocyanate from Dead Cell Apoptosis kit with Annexin V FITC and PI (eBioscience; Thermo Fisher Scientific, Inc.) was added to the cell suspension for $30 \mathrm{~min}$ at $4^{\circ} \mathrm{C}$ for labeling. Following washing with PBS for 5 min twice, propidium iodide or 7-aminoactinomycin D staining solution (eBioscience; Thermo Fisher Scientific, Inc.) was added at $4^{\circ} \mathrm{C}$ for $30 \mathrm{~min}$, followed by immediate detection of apoptosis in Eca109 cells using a flow cytometer (FACSCalibur ${ }^{\mathrm{TM}}$; BD Biosciences, San Jose, CA, USA). The cell cycle was analyzed with the DNA was labeled with nucleic acid dyes.

Statistical analysis. The data were presented mean \pm standard error of the mean. One-way analysis of variance followed by a least-significant difference test was performed using SPSS version 17.0 software (SPSS, Inc., Chicago, IL, USA). $\mathrm{P}<0.05$ was considered to indicate a statistically significant difference.

\section{Results}

EGFR protein expression. A total of three different sequences of siRNA, including EGFR siRNA ${ }_{1}$, EGFR siRNA 2 and EGFR siRNA ${ }_{3}$, were used to determine the most effective RNA interference sequence. Additionally, NC was included. Subsequently, the gray level of EGFR:NC was $0.7857 \pm 0.03581$, compared with NC (Fig. 1). The local expression of EGFR was increased in Eca109 cells with siRNAs.

Changes in cell proliferation. Growth inhibition was observed in the cells following exposure to nimotuzumab for 24 and $48 \mathrm{~h}$; additionally, there was growth inhibition following exposure to nimotuzumab for $72 \mathrm{~h}$. The rate of inhibition was increased with the concentration of nimotuzumab, which was notably increased when the concentration was $>250 \mu \mathrm{g} / \mathrm{ml}$. The $\mathrm{IC}_{50}$ of nimotuzumab was calculated as $768 \mu \mathrm{g} / \mathrm{ml}$ (Fig. 2).

Colony formation assay. Radiation biology parameters are presented in Table I. The SER of the 24NR, NR and 24RN groups were $1.09,0.99$ and 0.88 , respectively, at a dosage of $0.2 \mathrm{IC}_{50}(150 \mu \mathrm{g} / \mathrm{ml})$. The SER of the $24 \mathrm{NR}$, NR and $24 \mathrm{RN}$ groups were $1.22,1.04$ and 0.98 , respectively, at a dosage of $0.3 \mathrm{IC}_{50}(200 \mu \mathrm{g} / \mathrm{ml}$; Fig. 2). At these concentrations, the $24 \mathrm{NR}$ group demonstrated the greatest increase in radio sensitivity, compared with the other groups. Additionally, treatment with increased doses of nimotuzumab proportionally raised the radio sensitivity of cells. The survival curve of the 24NR group at $0.3 \mathrm{IC}_{50}$ demonstrated a notable decrease in SF compared with the R group (Fig. 3). This colony formation assay demonstrated that the $24 \mathrm{NR}$ group had reduced D0, compared with the NR group. 
A

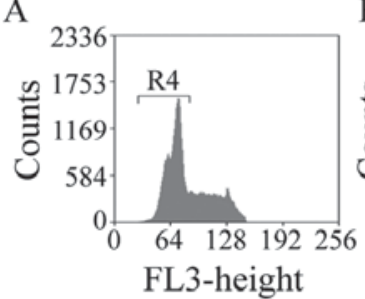

F

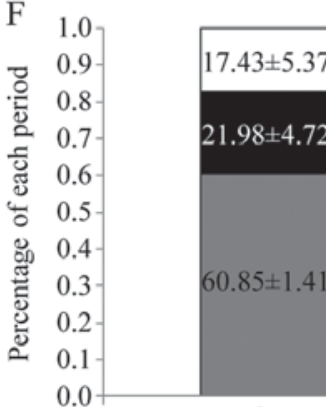

$\mathrm{O}$
B

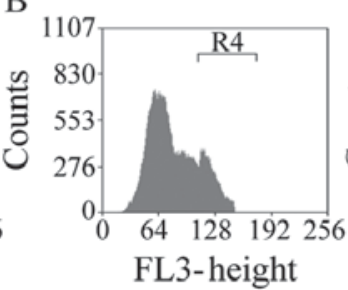

FL3-height
$\mathrm{C}$

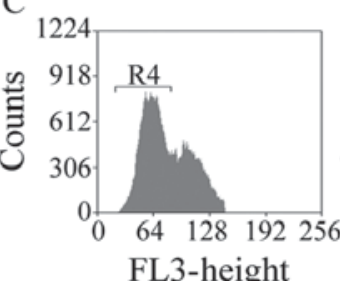

FL3-height
$\mathrm{D}$

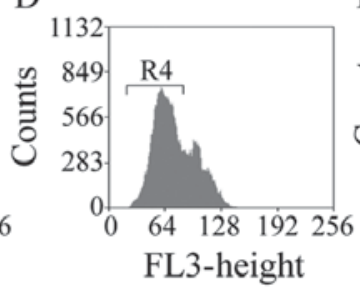

$\mathrm{E}$

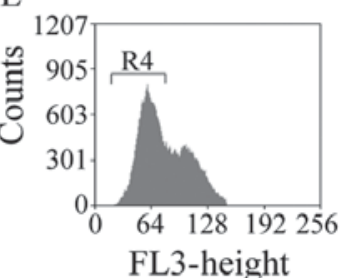

Figure 4. Cell cycle distribution in the five groups. Cell cycle distribution of the (A) O, (B) R, (C) 24NR, (D) NR and (E) 24RN groups. (F) The percentage of each period in the five groups. ${ }^{*} \mathrm{P}<0.05$, compared with group $\mathrm{O}$. O, control with no treatment; R, irradiation without nimotuzumab treatment; $24 \mathrm{NR}$, treatment with nimotuzumab $24 \mathrm{~h}$ prior to irradiation; $24 \mathrm{RN}$, treatment with nimotuzumab $24 \mathrm{~h}$ after irradiation; NR, nimotuzumab combined with irradiation simultaneously.

A
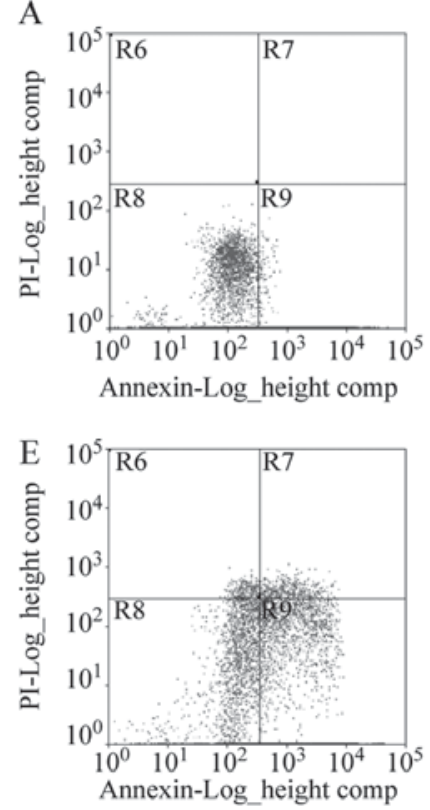

B

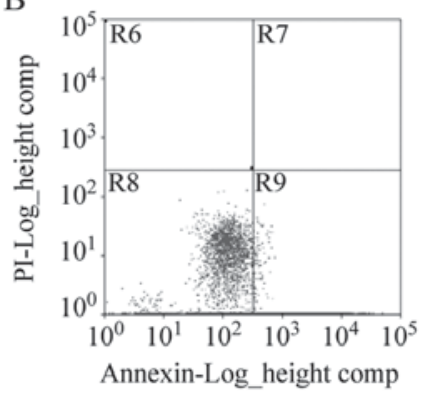

$\mathrm{F}$

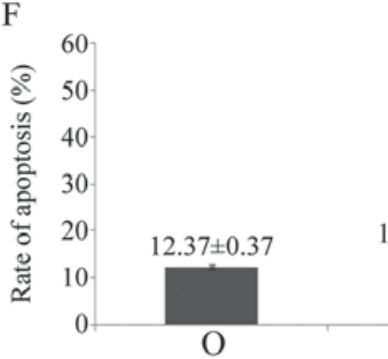

$\mathrm{C}$

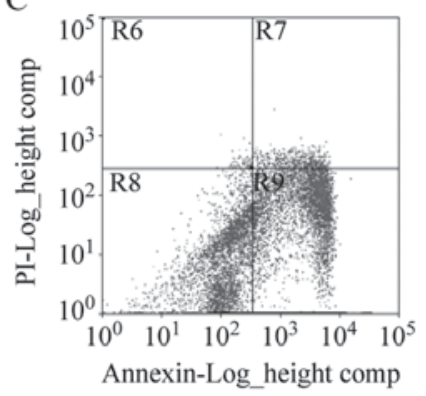

$\mathrm{D}$

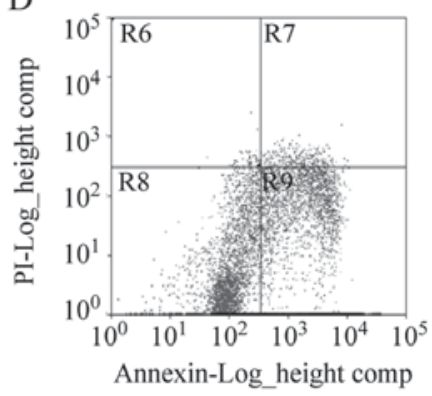

Figure 5. Cell apoptosis rate in the five groups. (A) O group. (B) R group. (C) 24NR group. (D) NR group. (E) $24 R N$ group. (F) The rate of apoptosis in the five groups. " $\mathrm{P}<0.05$, compared with $\mathrm{R}$ group. $\mathrm{O}$, control with no treatment; $\mathrm{R}$, irradiation without nimotuzumab treatment; $24 \mathrm{NR}$, treatment with nimotuzumab $24 \mathrm{~h}$ prior to irradiation; $24 \mathrm{RN}$, treatment with nimotuzumab $24 \mathrm{~h}$ after irradiation; NR, nimotuzumab combined with irradiation simultaneously.

Cell cycle distribution. Cell cycle distribution for each group is depicted in Fig. 4. The percentage of cells in the $\mathrm{G}_{2} / \mathrm{M}$ phase in the $\mathrm{R}$ group was significantly increased compared with that of the $\mathrm{O}$ control group, whereas the percentage of $\mathrm{S}$ phase cells was significantly reduced (both $\mathrm{P}<0.05$ ). In the 24NR, NR and 24RN groups, the proportion of the $\mathrm{S}$-phase cells decreased significantly, while the proportion of $\mathrm{G}_{2} / \mathrm{M}$-phase cells increased compared with the $\mathrm{O}$ control group (all $\mathrm{P}<0.05$ ), indicating that nimotuzumab and radiation exhibit a synergistic effect. Furthermore, the 24NR and NR groups demonstrated significant differences in the proportion of S-phase cells $(\mathrm{P}=0.041)$. Although an overall increase in $\mathrm{G}_{2}$ /M-phase cells was evident, no significant differences were reported between the three groups $(\mathrm{P}=0.62)$. Additionally, the 24NR group had increased proportions of $S$ and $G_{2} / M$-phase cells, compared with the $24 \mathrm{RN}$ or NR groups $(\mathrm{P}=0.53)$.

Cell apoptosis. Apoptosis rates for each group are depicted in Fig. 5. Nimotuzumab enhanced radiation-induced apoptosis in Eca109 cells at different delivery times. A significantly increased apoptosis ratio was observed in the $24 \mathrm{NR}$ $(56.01 \pm 0.54 ; \mathrm{P}=0.032), \mathrm{NR}(44.41 \pm 0.12 ; \mathrm{P}=0.025)$ and $24 \mathrm{RN}$ 
(38.12 $\pm 0.76 ; \mathrm{P}=0.036)$ groups, compared with the $\mathrm{R}$ group $(15.24 \pm 0.02)$. The apoptosis ratio was significantly increased in the 24NR group compared with NR $(\mathrm{P}=0.045)$ and $24 \mathrm{RN}$ $(\mathrm{P}=0.047)$ groups.

\section{Discussion}

In the present study, it was determined that the combination of EGFR inhibition and radiotherapy was more effective compared with individual treatment, which is consistent with another study (20). EGFR is an epidermal receptor with tyrosine kinase activity, which is usually over expressed in epithelial tumor types (21), including epithelial ovarian cancer (22), and breast tumor cells (23). Over expression of EGFR is associated with poor overall survival and increased rates of tumor recurrence, therefore it is an important target for treatment (24). Previous research has demonstrated that EGFR overexpression may regulate cell proliferation and assist tumor cells in avoiding apoptosis $(25,26)$. Additionally, monoclonal antibodies prevent the activation of this intracellular tyrosine kinase, thus inhibiting cell proliferation (27).

Nimotuzumab is a humanized monoclonal antibody. It blocks EGFR, and its downstream signals induce antibody-dependent cell-mediated cytotoxicity, tumor cytotoxicity and effectively stimulate EGFR internalization. Its anticancer properties have been demonstrated in vitro, and clinical trials have demonstrated that it is effective for treating tumor types of the head, neck and brain (28-30). Thus far, nimotuzumab has been used to treat $>4,000$ patients with milder side effects compared with those of cetuximab (31), although cetuximab has also been demonstrated to be more effective against advanced non-small cell lung cancer (NSCLC) (32). Numerous clinical studies have confirmed that treatment with EGFR inhibitors in combination with other therapies is effective and improves the prognosis of patients $(33,34)$. For example, treatment with nimotuzumab in combination with radiation and chemotherapy in head and neck cancer demonstrated positive results (35). Ramos-Suzarte et al (34) performed a phase II clinical trial where patients received radiotherapy, alone or combined with nimotuzumab, and determined that the objective response (15.4\% vs. $47.8 \%$, respectively) and disease control ( $26.9 \%$ vs. $60.9 \%$, respectively) rates were increased in the combination treatment group, compared with the control group.

The mechanisms of EGFR inhibitors include modifying signal transduction to enhance cellular radiosensitivity, killing cancer stem cells directly, inhibiting repair of DNA damage, reducing repopulation and improving reoxygenation during fractionated radiotherapy (35). Although EGFR inhibitors have been studied extensively, the optimal delivery time for EGFR inhibitors combined with radiation has not been determined, particularly for EC.

In the present study, the effect of delivery time on the effectiveness of EGFR inhibitors was investigated. A colony formation assay demonstrated that the 24NR group reduced D0, compared with the NR group. These results suggest that nimotuzumab enhances the radiosensitivity of Eca109 cells when combined with radiotherapy. The present study also demonstrated that the ratio of S-phase cells in the 24NR group and NR group was significantly reduced, compared with group $\mathrm{O}(\mathrm{P}<0.05)$, and the proportion of $\mathrm{G}_{2} / \mathrm{M}$-phase cells was increased in the 24NR, NR and 24RN groups, particularly the 24NR group. These results demonstrated that nimotuzumab has a weak effect on cell cycle distribution, but treatment with nimotuzumab $24 \mathrm{~h}$ prior to irradiation is most effective. Cells exposed to nimotuzumab in combination with radiation had an increased apoptosis ratio, compared with cells treated with radiation only. Generally, the cell cycle stagnates at the same phase to repair damage and prevent apoptosis (36). Radiation therapy arrested the cell cycle at the $\mathrm{G}_{2} / \mathrm{M}$ phase, where multiple growth factors would be required to repair it (37). When the EGFR signal pathway is blocked by nimotuzumab, cells undergo apoptosis as they lack the necessary growth factors (38).

Western blotting demonstrated that EGFR is expressed in Eca109 cells. A number of studies have determined that no significant association between EGFR expression levels and the antitumor effects of EGFR inhibitors (39-41). Garrido et al (35) observed that nimotuzumab selectively binds to cells with moderate to high EGFR expression levels, and its antitumor capabilities decreased proportionally with EGFR expression levels. In contrast, the efficacy of cetuximab does not appear to depend on EGFR expression levels. Zhao et al (40) demonstrated that nimotuzumab enhances the radiation response and increases the rate of radiation-mediated apoptosis in KYSE30 cells that exhibit high EGFR activity; however, these effects were not observed in TE-1 cells that exhibit low EGFR activity. Akashi et al (41) examined the effects of nimotuzumab combined with radiation therapy on human NSCLC cell lines with different EGFR expression levels, and determined that nimotuzumab enhances the effectiveness of radiation therapy in human NSCLC cell lines with high levels of EGFR expression, in vitro and in vivo. These trials demonstrated that the radiosensitivity of nimotuzumab depends on the expression levels of EGFR. Nimotuzumab and cetuximab are antibodies that inhibit ligand binding upon interaction with EGFR, thereby indirectly inactivating the EGFR kinase. Nimotuzumab has a reduced binding affinity for EGFR, compared with cetuximab. In EGFR-overexpressing cells, nimotuzumab inhibits EGFR-stimulated signaling and ligand-independent basal signaling (42). Additionally, cetuximab is effective at reduced concentrations (43). Compared with the study by Yang et al (44), where different cell lines were used, the present study used one cell line. The present study focused on different delivery times in the mixed cancer Eca109 cell line, which is comparative to the study by Yang et al (44). Additionally, Yang et al (44) focused on the combined use of h-R3 with cisplatin and fluorouracil and determined that the sensitization effect of h-R 3 on chemotherapy drugs is associated with the expression level of EGFR in EC1 or EC9706 cells. Furthermore, in the present study it was demonstrated that the concentration of Nimotuzumab administered was directly proportional to the increase in radiosensitivity of the cells (44). The present study demonstrated that treatment with nimotuzumab in combination with radiation affected cell cycle distribution, and enhanced radiation-induced apoptosis and radiosensitivity in human Eca109 cells. The absence of RT-qPCR data is one of the limitations of the present study. Additionally, due to only one cell line being used in the present study, the significance of these data is limited. 
In conclusion, the present study demonstrated that the most optimal radiosensitizing effect was observed in the ESCC Eca109 cell line when nimotuzumab was delivered $24 \mathrm{~h}$ prior to radiation. The concentration of nimotuzumab administered was directly proportional to the increase in radiosensitivity. Furthermore, due to the effects of nimotuzumab-induced radiosensitization in vivo being more complicated than in vitro, future studies should focus on in vivo experiments to confirm the effects of nimotuzumab.

\section{Acknowledgements}

The authors would like to thank Professor Fuzhou Chen (Fujian Provincial Tumor Hospital, Fuzhou, China) for critical reading.

\section{Funding}

No funding was received.

\section{Availability of data and materials}

All data generated or analyzed during this study are included in this published article.

\section{Authors' contributions}

JL and LW conceived and designed the experiments. LW, YS and JL performed the experiments. ZQ and JL analyzed the data. ZQ and YS contributed reagents, materials and analysis tools.

\section{Ethics approval and consent to participate}

Not applicable.

\section{Patient consent for publication}

Not applicable.

\section{Competing interests}

The authors declare that they have no competing interests.

\section{References}

1. Bray F, Jemal A, Grey N, Ferlay J and Forman D: Global cancer transitions according to the Human Development Index (2008-2030): A population-based study. Lancet Oncol 13: 790-801, 2012

2. Baba Y, Saeki H, Nakashima Y, Oki E, Shigaki H, Yoshida N, Watanabe M, Maehara Y and Baba H: Review of chemotherapeutic approaches for operable and inoperable esophageal squamous cell carcinoma. Dis Esophagus 30: 1-7, 2017.

3. Tamaki Y, Hieda Y, Nakajima M, Kitajima K, Yoshida R, Yoshizako T, Ue A, Tokudo M, Hirahara N, Moriyama I, et al: Concurrent chemoradiotherapy with docetaxel, cisplatin, and 5 -fluorouracil improves survival of patients with advanced esophageal cancer compared with conventional concurrent chemoradiotherapy with cisplatin and 5-fluorouracil. J Cancer 9: 2765-2772, 2018.

4. Fokas E, Weiss C and Rodel C: The role of radiotherapy in the multimodal management of esophageal cancer. Diq Dis 31: 30-37, 2013.
5. Wang Q, Zhu H, Xiao Z, Zhang W, Liu X, Zhang X, He J, Sun K, Wang L and $\mathrm{Xu} \mathrm{N}$ : Expression of epidermal growth factor receptor is an independent prognostic factor for esophageal squamous cell carcinoma. World J Surg Oncol 11: 278, 2013.

6. Abdo J, Agrawal DK and Mittal SK: Basis for molecular diagnostics and immunotherapy for esophageal cancer. Expert Rev Anticancer Ther 17: 33-45, 2017.

7. Hong L, Han Y and Brain L: Epidermal growth factor receptor: An important target in esophageal cancer. Expert Opin Ther Targets 17: 1179-1185, 2013.

8. Sasada T, Azuma K, Ohtake J and Fujimoto Y: Immune responses to epidermal growth factor receptor (EGFR) and their application for cancer treatment. Front Pharmacol 7: 405, 2016.

9. Cohen RB: Current challenges and clinical investigations of epidermal growth factor receptor (EGFR)- and ErbB family-targeted agents in the treatment of head and neck squamous cell carcinoma (HNSCC). Cancer Treat Rev 40: 567-577, 2014.

10. Chi A, Remick S and Tse W: EGFR inhibition in non-small cell lung cancer: Current evidence and future directions. Biomark Res 1: 2, 2013.

11. Cohen EE, Rosen F, Stadler WM, Recant W, Stenson K, Huo D and Vokes EE: Phase II trial of ZD1839 in recurrent or metastatic squamous cell carcimoma of the head and neck. J Clin Oncol 21: 1980-1987, 2003.

12. Chan CM, Ma BB, Wong SC and Chan AT: Celecoxib induces dose dependent growth inhibition in nasopharygeal carcinoma cell lines independent of cyclooxygenase-2 expression. Biomed Phamacother 59: S268-S271, 2005.

13. Provencio M and Sánchez A: Therapeutic integration of new molecule-targeted therapies with radiotherapy in lung cancer. Transl Lung Cancer Res 3: 89-94, 2014.

14. Chinnaiyan P, Huang S, Vallabhaneni G, Armstrong E, Varambally S, Tomlins SA, Chinnaiyan AM and Harari PM: Mechanisms of enhanced radiation response following epidermal grow th factor receptor signaling inhibition by erlotinib (Tarceva). Cancer Res 65: 3328-3335, 2005.

15. Ku GY and Ilson DH: Emerging tyrosine kinase inhibitors for esophageal cancer. Expert Opin Emerg Drugs 18: 219-230, 2013.

16. Lu M, Wang X, Shen L, Jia J, Gong J, Li J, Li J, Li Y, Zhang X, Lu Z, et al: Nimotuzumab plus paclitaxel and cisplatin as the first line treatment for advanced esophageal squamous cell cancer: A single centre prospective phase II trial. Cancer Sci 107: 486-490, 2016.

17. Diaz-Miqueli A and Martinez GS: Nimotuzumab as a radiosensitizing agent in the treatment of high grade glioma: Challenges and opportunities. Onco Targets Ther 6: 931-942, 2013.

18. Jiang T, Min W, Li Y, Yue Z, Wu C and Zhou C: Radiotherapy plus EGFR TKIs in non-small cell lung cancer patients with brain metastases: An update meta-analysis. Cancer Med 5: 1055-1065, 2016.

19. Ye F, Chen C, Qin J, Liu J and Zheng C: Genetic profiling reveals an alarming rate of cross-contamination among human cell lines used in China. FASEB J 29: 4268-4272, 2015.

20. Crombet T, Osorio M, Cruz T, Roca C, del Castillo R, Mon R, Iznaga-Escobar N, Figueredo R, Koropatnick J, Renginfo E, et al: Use of the humanized anti-epidermal growth factor receptor monoclonal antibody h-R3 in combination with radiotherapy in the treatment of locally advanced head and neck cancer patients. J Clin Oncol 22: 1646-1654, 2004.

21. Mukhopadhyay C, Zhao X, Maroni D, Band V and Naramura M: Distinct effects of EGFR ligands on human mammary epithelial cell differentiation. PLoS One 8: e75907, 2013.

22. Zhou X, Hu Y, Dai L, Wang Y, Zhou J, Wang W, Di W and Qiu L: MicroRNA-7 inhibits tumor metastasis and reverses epithelial-mesenchymal transition through AKT/ERK1/2 inactivation by targeting EGFR in epithelial ovarian cancer. PLoS One 9: e96718, 2014.

23. Andrade SS, Sumikawa JT, Castro ED, Batista FP, Paredes-Gamero E, Oliveira LC, Guerra IM, Peres GB, Cavalheiro RP, Juliano L, et al: Interface between breast cancer cells and the tumor microenvironment using platelet-rich plasma to promote tumor angiogenesis-influence of platelets and fibrin bundles on the behavior of breast tumor cells. Oncotarget 8: 16851-16874, 2017.

24. Navarini D, Gurski RR, Madalosso CA, Aita L, Meurer L and Fornari F: Epidermal growth factor receptor expression in esophageal adenocarcinoma: Relationship with tumor stage and survival after esophagectomy. Gastroenterol Res Pract 2012: 941954, 2012. 
25. Szabó B, Nelhubel GA, Kárpáti A, Kenessey I, Jóri B, Székely C Peták I, Lotz G, Hegedus Z, Hegedus B, et al: Clinical significance of genetic alterations and expression of epidermal growth factor receptor (EGFR) in head and neck squamous cell carcinomas. Oral Oncol 47: 487-496, 2011.

26. Park HS, Jang MH, Kim EJ, Kim HJ, Lee HJ, Kim YJ, Kim JH, Kang E, Kim SW, Kim IA and Park SY: High EGFR gene copy number predicts poor outcome in triple-negative breast cancer Mod Pathol 27: 1212-1222, 2014.

27. Ayyappan S, Prabhakar D and Sharma N: Epidermal growth factor receptor (EGFR)-targeted therapies in esophagogastric cancer. Anticancer Res 33: 4139-4155, 2013.

28. Wang Y, Pan L, Sheng XF, Chen S and Dai JZ: Nimotuzumab, a humanized monoclonal antibody specific for the EGFR, in combination with temozolomide and radiation therapy for newly diagnosed glioblastoma multiforme: First results in Chinese patients. Asia Pac J Clin Oncol 12: e23-e29, 2016.

29. Nitta Y, Shimizu S, Shishido-Hara Y, Suzuki K, Shiokawa Y and Nagane M: Nimotuzumab enhances temozolomide-induced growth suppression of glioma cells expressing mutant EGFR in vivo. Cancer Med 5: 486-499, 2016.

30. Chong DQ, Toh XY, Ho IA, Sia KC, Newman JP, Yulyana Y, Ng WH, Lai SH, Ho MM, Dinesh N, et al: Combined treatment of Nimotuzumab and rapamycin is effective against temozolomide-resistant human gliomas regardless of the EGFR mutation status. BMC Cancer 15: 255, 2015.

31. Boland WK and Bebb G: Nimotuzumab: A novel anti-EGFR monoclonal antibody that retains anti-EGFR activity while minimizing skin toxicity. Expert Opin Biol Ther 9: 1199-1206, 2009.

32. Gridelli C, Maione P, Ferrara ML and Rossi A: Cetuximab and other anti-epidermal growth factor receptor monoclonal antibodies in the treatment of non-small cell lung cancer. Oncologist 14: 601-611, 2009.

33. Basavaraj C, Sierra P, Shivu J, Melarkode R, Montero E and Nair P: Nimotuzumab with chemoradiation confers a survival advantage in treatment-naïve head and neck tumors over expressing EGFR. Cancer Biol Ther 10: 673-681, 2010.

34. Ramos-Suzarte M, Lorenzo-Luaces P, Lazo NG, Perez ML, Soriano JL, Gonzalez CE, Hernadez IM, Albuerne YÁ, Moreno BP, Alvarez ES, et al: Treatment of malignant, non-resectable, epithelial origin esophageal tumours with the humanized anti-epidermal growth factor antibody nimotuzumab combined with radiation therapy and chemotherapy. Cancer Biol Ther 13: 600-605, 2012.

35. Baumann M, Krause M, Dikomey E, Dittmann K, Dörr W, Kasten-Pisula U and Rodemann HP: EGFR-targeted anti-cancer drugs in radiotherapy: Preclinical evaluation of mechanisms. Radiother Oncol 83: 238-248, 2007.
36. Shaltiel IA, Krenning L, Bruinsma W and Medema RH: The same, only different -DNA damage checkpoints and their reversal throughout the cell cycle. J Cell Sci 128: 607-620, 2015.

37. Fan QW and Weiss WA: RNA interference against a glioma-derived allele of EGFR induces blockade at G2M. Oncogene 24: 829-837, 2005.

38. Lin S, Yan Y,Liu Y, Gao CZ, Shan D, Li Y and Han B: Sensitisation of human lung adenocarcinoma A549 cells to radiotherapy by Nimotuzumab is associated with enhanced apoptosis and cell cycle arrest in the G2/M phase. Cell Biol Int 39: 146-151, 2015.

39. Garrido G, Tikhomirov IA, Rabasa A, Yang E, Gracia E, Iznaga N, Fernández LE, Crombet T, Kerbel RS and Pérez R: Bivalent binding by intermediate affinity of nimotuzumab: A contribution to explain antibody clinical profile. Cancer Biol Ther 11: 373-382, 2011.

40. Zhao L, He LR, Xi M, Cai MY, Shen JX, Li QQ, Liao YJ, Qian D, Feng ZZ, Zeng YX, et al: Nimotuzumab promotes radiosensitivity of EGFR-overexpression esophageal squamous cell carcinoma cells by upregulating IGFBP-3. J Transl Med 10: 249, 2012

41. Akashi Y, Okamoto I, Iwasa T, Yoshida T, Suzuki M, Hatashita E, Yamada Y, Satoh T, Fukuoka M, Ono K and Nakagawa K: Enhancement of the antitumor activity of ionising radiation by nimotuzumab, a humanised monoclonal antibody to the epidermal growth factor receptor, in non-small cell lung cancer cell lines of differing epidermal growth factor receptor status. $\mathrm{Br}$ J Cancer 98: 749-755, 2008.

42. Liu H, Yang W, Gao H, Jiang T, Gu B, Dong Q, Xu W, Wu S and Sun X: Nimotuzumab abrogates acquired radioresistance of KYSE-150R esophageal cancer cells by inhibiting EGFR signaling and cellular DNA repair. Onco Targets Ther 8: 509-518, 2015.

43. Berger C, Krengel U, Stang E, Moreno E and Madshus IH: Nimotuzumab and cetuximab block ligand-independent egf receptor signaling efficiently at different concentrations. J Immunother 34: 550-555, 2011.

44. Yang X, Ji Y, Kang X, Chen M, Kou W, Jin C and Lu P: Study on chemotherapeutic sensitizing effect of nimotuzumab on different human esophageal squamous carcinoma cells. Oncol Lett 11: 973-978, 2016

This work is licensed under a Creative Commons Attribution-NonCommercial-NoDerivatives 4.0 International (CC BY-NC-ND 4.0) License. 